\title{
Pharmacokinetic and pharmacodynamic analysis of fulvestrant in preclinical models of breast cancer to assess the importance of its estrogen receptor-a degrader activity in antitumor efficacy
}

\author{
Suzanne E. Wardell ${ }^{1}$ Alexander P. Yllanes ${ }^{1}$. Christina A. Chao ${ }^{1}$. Yeeun Bae ${ }^{1}$ Kaitlyn J. Andreano ${ }^{1}$. \\ Taylor K. Desautels ${ }^{1} \cdot$ Kendall A. Heetderks ${ }^{1} \cdot$ Jeremy T. Blitzer $^{2} \cdot$ John D. Norris ${ }^{1} \cdot$ Donald P. McDonnell $^{1}$ (I)
}

Received: 13 September 2019 / Accepted: 19 September 2019 / Published online: 27 September 2019

(c) The Author(s) 2019, corrected publication 2019

\begin{abstract}
Purpose Fulvestrant is a selective estrogen receptor downregulator (SERD) that is approved for first- or second-line use as a single agent or in combination with cyclin dependent kinase or phosphatidylinositol 3-kinase inhibitors for the treatment of metastatic breast cancer. Fulvestrant exhibits exceptionally effective antitumor activity in preclinical models of breast cancer, a success that has been attributed to its robust SERD activity despite modest receptor downregulation in patient tumors. By modeling human exposures in animal models we probe the absolute need for SERD activity.

Methods Three xenograft models of endocrine therapy-resistant breast cancer were used to evaluate the efficacy of fulvestrant administered in doses historically used in preclinical studies in the field or by using a dose regimen intended to model clinical exposure levels. Pharmacokinetic and pharmacodynamic analyses were conducted to evaluate plasma exposure and intratumoral ER downregulation.

Results A clinically relevant $25 \mathrm{mg} / \mathrm{kg}$ dose of fulvestrant exhibited antitumor efficacy comparable to the historically used $200 \mathrm{mg} / \mathrm{kg}$ dose, but at this lower dose it did not result in robust ER downregulation. Further, the antitumor efficacy of the lower dose of fulvestrant was comparable to that observed for other oral SERDs currently in development.

Conclusion The use of clinically unachievable exposure levels of fulvestrant as a benchmark in preclinical development of SERDs may negatively impact the selection of those molecules that are advanced for clinical development. Further, these studies suggest that antagonist efficacy, as opposed to SERD activity, is likely to be the primary driver of clinical response.
\end{abstract}

Keywords Selective estrogen receptor downregulator $\cdot$ Fulvestrant $\cdot$ Endocrine resistant breast cancer

\section{Background}

Estrogens play a critical role in the development of female reproductive tissues and contributes to the development and progression of breast cancer. Patients that present with estrogen receptor $\alpha$ (ER)-positive disease are generally treated

Electronic supplementary material The online version of this article (https://doi.org/10.1007/s10549-019-05454-y) contains supplementary material, which is available to authorized users.

Donald P. McDonnell

donald.mcdonnell@duke.edu

1 Department of Pharmacology and Cancer Biology, Duke University School of Medicine, Box 3813, Durham, NC 27710, USA

2 Potrero Hill Therapeutics, San Francisco, CA 94110, USA with an antiendocrine therapy in the adjuvant setting, consisting of either the selective estrogen receptor modulator (SERM) tamoxifen or an aromatase inhibitor (AI, e.g., anastrozole, letrozole, exemestane) [1]. These adjuvant therapies have proven effective to reduce the incidence of progression to metastatic disease. Patients that present with or progress to advanced metastatic breast cancer are also typically treated with an antiendocrine therapy as part of a more aggressive treatment regimen [2]. In this setting, these treatments are not curative, with a significant number of cancers exhibiting de novo or rapidly acquired resistance to existing antiestrogens and aromatase inhibitors. After progression during SERM and AI therapy, other endocrine therapies can be effective, including the steroidal selective estrogen receptor degrader (SERD) fulvestrant, megestrol acetate (a progesterone receptor agonist), or high-dose estrogens [3-5]. 
SERDs are a particularly intriguing option because they have the dual action of both eliminating ER expression and directly inhibiting activity. The first drug of the SERD class to be developed, fulvestrant (faslodex), demonstrated efficacy in preclinical in vitro and in vivo models of breast cancer either sensitive or resistant to tamoxifen (standard of care breast cancer treatment at that time) and entered clinical trials with the expectation of similar efficacy in the treatment of relapsed/progressing breast tumors [6-8]. Despite ongoing efforts by several academic and commercial entities to develop an oral SERD, fulvestrant remains the only drug in this class approved for the treatment of breast cancer.

Since its initial preclinical evaluation in xenograft tumor models in mice [7], fulvestrant is generally administered as a weekly injection of $5 \mathrm{mg} /$ mouse $(\sim 200 \mathrm{mg} / \mathrm{kg}$, depending on strain). However, the body surface area (BSA) based inter-species conversion calculation embraced by the US Food and Drug Administration indicates that a mouse dose equivalent to that used clinically would be $100 \mathrm{mg} / \mathrm{kg}$ per four-week cycle ( $25 \mathrm{mg} / \mathrm{kg} /$ week) [9]. While an argument can be made that the more rapid turnover of mouse serum albumin ( 3 days vs. 3 weeks in humans) might require a higher exposure, there remains a clear possibility that the dosing regimen widely used preclinically in mouse studies likely exceeds that approved for clinical use by 8 -fold, overestimating its potential activity and inappropriately setting the benchmark for other therapies. Therefore, we sought to conduct a thorough PK/PD analysis of fulvestrant exposure in mice and relate this to efficacy in relevant breast cancer tumor models. We further probed the relationship between drug exposure, antitumor efficacy, and receptor turnover, an exceptionally important unanswered question in this field.

\section{Materials and methods}

\section{Reagents and source}

Tamoxifen treatment pellets were purchased from Innovative Research of America. Fulvestrant, AZD9496, GDC0810, and bazedoxifene were purchased from MedChemExpress. Estradiol was purchased from Sigma-Aldrich, Inc. Antibodies used for immunoblot detection included the following: estrogen receptor (ER)-HC-20 or H184, Santa Cruz Biotechnology; actin-A5441, Sigma-Aldrich, Inc.; vinculin13901S, Cell Signaling.

\section{Xenograft tumor studies}

All procedures were approved by the Duke University Institutional Animal Care and Use Committee (IACUC) prior to initiating the experiment.

\section{TamR study 1}

TamR tumors were implanted orthotopically $\left(8 \mathrm{~mm}^{3}\right.$ fragment inserted sc into the mammary fat pad) into 65 ovariectomized tamoxifen-treated ( $5 \mathrm{mg} / 60$ days pellet, Innovative Research of America) female $N u / J$ mice ( 6 weeks of age). Tumor volume and body weight were measured $3 \mathrm{X}$ weekly until tumors reached $\sim 0.1-0.15 \mathrm{~cm}^{3}$ volume $\left(l \times w^{2} \times 0.5\right)$. Mice were then randomized $(n=8-9)$ to 4 weekly treatments with $0,25,50,100$, or $200 \mathrm{mg} / \mathrm{kg}$ fulvestrant injected sc $(5 \%$ DMSO/95\% corn oil) with continued tumor measurement and weight monitoring. After 28 days of treatment, animals were euthanized by $\mathrm{CO}_{2}$ exposure, followed immediately by cardiac puncture for blood collection. Plasma and tumor tissues were cryopreserved for future analysis.

\section{TamR study 2}

50 female $N u / J$ mice were ovariectomized and received Tam treatment pellet, tumor implantation, and monitoring as described above. When tumors reached $\sim 0.1-0.15 \mathrm{~cm}^{3}$ volume, mice were randomized $(n=8)$ to daily po treatment with vehicle (9/0.5/0.5/90 PEG 400/PVP/Tween 80/0.5\% CMC), AZD9496 (10 mg/kg), GDC0810 (25 mg/kg), or bazedoxifene $(12.5 \mathrm{mg} / \mathrm{kg})$. After 28 days of treatment, animals were euthanized and tissues harvested as above.

\section{LTED study}

65 female $N u / J$ mice were ovariectomized and 1 week later LTED tumor fragments were implanted orthotopically as described above and similarly monitored. Mice were then randomized $(n=8-9)$ to daily po treatment with vehicle (9/0.5/0.5/90 PEG 400/PVP/Tween 80/0.5\% CMC), AZD9496 (10 mg/kg), GDC0810 (25 mg/kg), or bazedoxifene $(12.5 \mathrm{mg} / \mathrm{kg})$. Fulvestrant-treated mice $(25 \mathrm{mg} / \mathrm{kg} \mathrm{sc}$ weekly) also received daily treatment with vehicle po. After 28 days of treatment, animals were euthanized and tissues harvested as above.

\section{HCC1428 study}

40 female $N u / J$ mice were ovariectomized with concurrent initiation of estradiol treatment $(0.75 \mu \mathrm{g} / \mathrm{ml}$ in drinking water). Fragments of an HCC1428 xenograft tumor were implanted as described above. When tumors reached $\sim 0.1-0.15 \mathrm{~cm}^{3}$ volume, animals were randomized to weekly injection of vehicle or $25 \mathrm{mg} / \mathrm{kg}$ fulvestrant (as above).

\section{Immunoblot analysis of tumor tissue}

Frozen tissues were pulverized under $\mathrm{LN}_{2}$ prior to protein extraction of powdered tissues using RIPA buffer $(50 \mathrm{mM}$ 
Tris, $\mathrm{pH} 8,150 \mathrm{mM} \mathrm{NaCl}, 1 \% \mathrm{NP}-40,0.5 \%$ deoxycholate, $0.02 \%$ SDS, $1 \mathrm{mM}$ EDTA). $25 \mu \mathrm{g}$ of cleared extracts were resolved by SDS-PAGE prior to transfer to PVDF membrane and immunoblot analysis by standard methods. Bands detected were quantitated using ImageJ per standard methods [10].

\section{Real-time quantitative PCR analysis of tumor tissue}

Total RNA was extracted from pulverized frozen tissues using the Aurum total RNA extraction kit (Bio-Rad) as per kit instructions. Following cDNA synthesis (iScript, BioRad), RT-qPCR analysis of cDNA samples was performed using iQ SYBR Green Supermix (Bio-Rad). mRNA abundance was calculated using the $\Delta \Delta \mathrm{C}_{\mathrm{T}}$ method [11].

\section{Statistical analyses}

Tumor growth data were subjected to exponential growth curve analysis constrained to share an initial value, and to 2-way ANOVA analysis followed by Bonferroni multiple comparison test. Significant differences as compared to the vehicle treated control $(p<0.05)$ were detected for multiple groups at several time points (indicated on graphs). Groups showed equivalent variance (10-15\% with normal distribution) throughout all time points, justifying the statistical analyses that were selected. ER expression levels were evaluated using 1-way ANOVA analysis followed by Bonferroni multiple comparison test. Percent tumor growth inhibition (TGI) at each day of measurement was calculated using the equation $\% \mathrm{TGI}=[1-($ mean tumor volume of treated $) /($ mean tumor volume of vehicle)].

\section{Results}

\section{Fulvestrant exhibits antitumor efficacy in breast cancer tumors at a clinically relevant dose}

As a first step to evaluate in vivo exposure of fulvestrant in mice, we initially conducted a simple PK analysis in which $N u: J$ mice received a single injection of 25 or $200 \mathrm{mg} / \mathrm{kg}$ fulvestrant, and plasma was collected for analysis from mice euthanized $1,3,5$, or 7 days after administration. The circulating levels of fulvestrant in plasma samples retained were evaluated by LC/MS/MS analysis. Both doses resulted in highest levels detected 1 day after administration (Fig. 1a), but the ensuing plateau observed for the $25 \mathrm{mg} / \mathrm{kg}$ dose best approximated the approximate $28 \mathrm{ng} / \mathrm{ml} \mathrm{C}_{\max }$ observed per current protocol in patients [12].

In order to assess the relationship between dose and efficacy of fulvestrant on the growth of a clinically relevant xenograft model of endocrine therapy-resistant breast cancer, tamoxifen-resistant (TamR) xenograft tumors were established orthotopically in ovariectomized tamoxifen-treated ( $5 \mathrm{mg} / 60$ days administered by continuous release pellet) female $N u: J$ mice. When tumors measured $0.1-0.15 \mathrm{~cm}^{3}$ volume, mice were randomized to 4 weekly injections with Vehicle or fulvestrant $(25,50,100$, or $200 \mathrm{mg} / \mathrm{kg})$. A significant inhibition of tumor growth was observed for all doses of fulvestrant as compared to the vehicle control (Fig. 1b), and no significant differences could be detected between doses.

Circulating plasma levels of fulvestrant present at euthanasia ( 7 days after final dose) were evaluated as above (Fig. 1c). A linear relationship between dose and plasma levels was noted, with mean values of 34.6, 64.9, 95.6, and $207 \mathrm{ng} / \mathrm{ml}(57,107,157$, and $340 \mathrm{nM})$ being detected for $25,50,100$, and $200 \mathrm{mg} / \mathrm{kg}$ doses, respectively. It is worth noting that after 4 weekly administrations, the circulating plasma levels observed for the $25 \mathrm{mg} / \mathrm{kg}$ dose best approximated the clinical $\mathrm{C}_{\max }$, as would be expected using the BSA calculation.

The efficient tumor growth inhibition observed for fulvestrant at doses several fold lower than the $200 \mathrm{mg} / \mathrm{kg}$ dose historically used preclinically led us to evaluate the pharmacodynamic relationship between the dose administered and ER downregulation, as the clinical efficacy of fulvestrant has been attributed at least in part to its ability to reduce ER expression. A dose dependent downregulation of ER expression was observed in the harvested tumor tissues when evaluated by immunoblot of the cleared lysates derived from fulvestrant-treated tumors (relative ER levels are presented in Fig. 1d, primary blots are included in Online Resource 1a). Interestingly, for those tumors treated with the $25 \mathrm{mg} /$ $\mathrm{kg}$ dose, a wide range of ER levels were detected, which is again reminiscent of the clinical observations with fulvestrant, as the extent of ER downregulation observed comparing pre- and post-treatment biopsies can vary widely [13]. Significant $(p<0.001)$ downregulation of ER was observed only for 50,100 , and $200 \mathrm{mg} / \mathrm{kg}$ doses despite equivalent inhibition of tumor growth by all doses administered. These data question the importance of SERD activity to the antitumor efficacy of fulvestrant.

To evaluate further the relationship between ER downregulation and inhibition of ER activity, the mRNA expression of ER target genes known to be responsive to tamoxifen in this tumor model (Online Resource 1b) was evaluated by real-time quantitative PCR (RT-qPCR). As shown in Fig. 1e, all of the doses of fulvestrant administered resulted in dramatic downregulation of the expression of anterior gradient protein 3 (AGR3) and keratin 13 (KRT13). Interestingly, a modest reduction in AGR2 expression was observed only for those doses of fulvestrant that resulted in quantitative downregulation of ER protein. This latter result is consistent with previous findings from our laboratory demonstrating an enhancer switch in the $A G R 2$ gene in this tamoxifen-resistant 

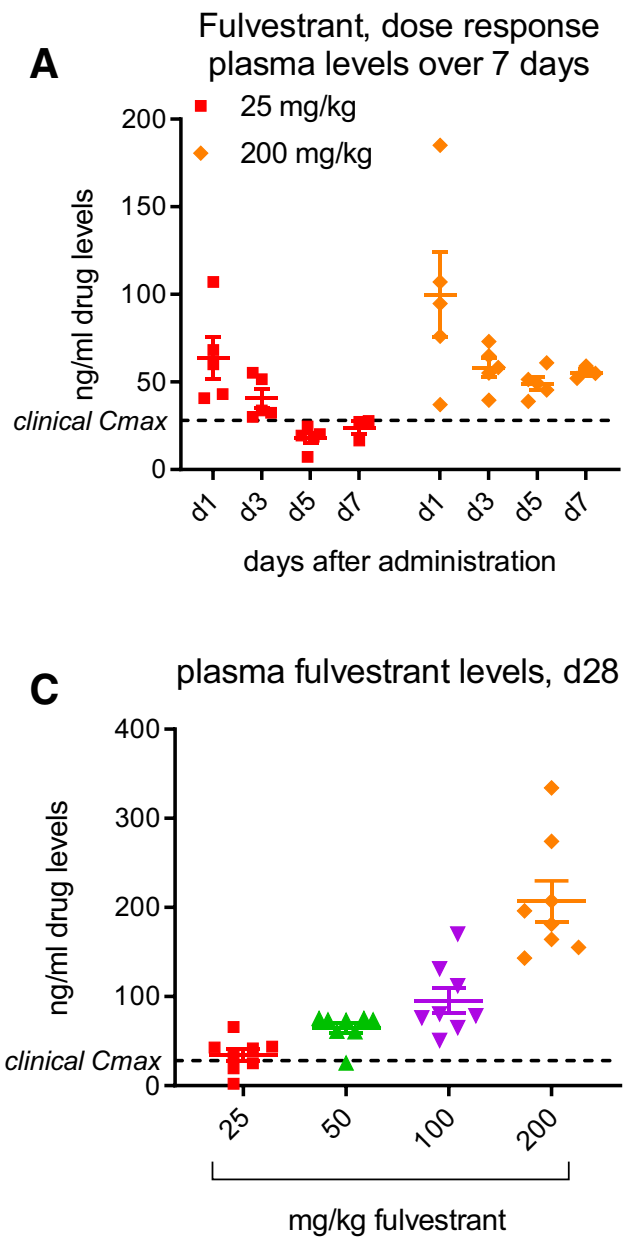
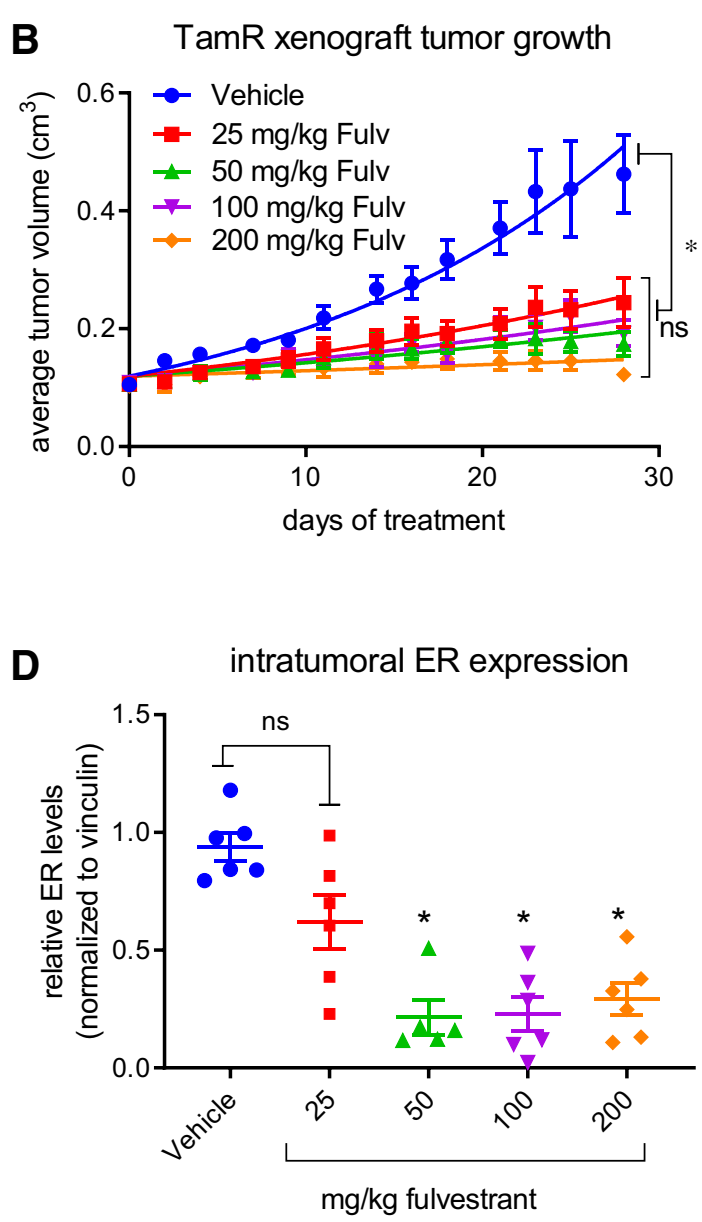

\section{E}

AGR2

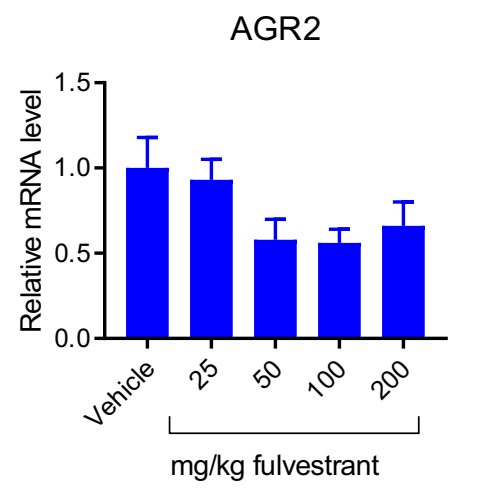

Intratumoral expression of ER target genes

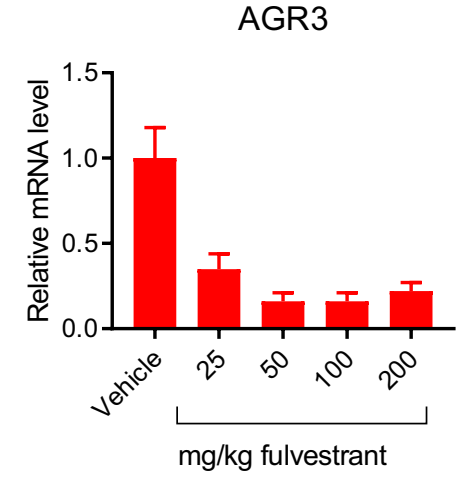

KRT13

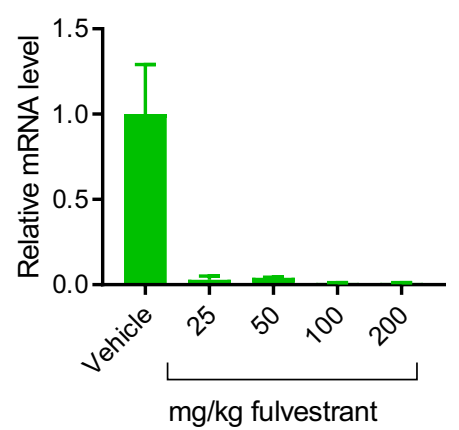

Fig. 1 Evaluation of PK/PD and efficacy of fulvestrant in an endocrine therapy-resistant tumor model. a Circulating plasma levels of fulvestrant in $N u: J$ mice $1,3,5$, or 7 days following a single administration of 25 or $200 \mathrm{mg} / \mathrm{kg}$ fulvestrant. Detection of fulvestrant in mouse plasma was conducted via LC/MS/MS (Confluence Discovery Technologies, Saint Louis, MO). b Tamoxifen-treated $N u: J$ mice bearing TamR (tamoxifen-resistant) xenograft tumors were randomized to treatment with vehicle or fulvestrant $(25-200 \mathrm{mg} / \mathrm{kg})$. Data presented indicate the average tumor volume for each group $($ mean \pm SEM) at each time point. *Significant $(p>0.05)$ inhibition of tumor growth was observed for all doses of fulvestrant (2-way
ANOVA analysis followed by Bonferroni multiple comparison test). c Levels of fulvestrant were evaluated in plasma retained from mice included in (b). d ER levels present in tumors harvested from mice included in $\mathbf{b}$ were analyzed by western blotting of tissue extracts. A significant decrease in ER levels was observed for 50, 100, and $200 \mathrm{mg} / \mathrm{kg}$ doses $* p<0.05$ (1-way ANOVA analysis followed by Bonferroni multiple comparison test). Primary western blot images are included in Suppl. Fig. 1. e The expression of tamoxifen responsive ER target genes AGR2, AGR3, and KRT13 in cDNA generated from tumors harvested in $\mathbf{b}$ were analyzed by RT-qPCR 
tumor model, thereby reducing the dependence of $A G R 2$ expression on ER activity [14].

\section{When administered at a clinically relevant dose, SERDs exhibit similar efficacy and pharmacodynamics}

We and others have previously conducted in vivo studies comparing the efficacy of oral SERDs and fulvestrant [15-17]. One similarity between these studies is the greater effectiveness generally observed for fulvestrant $(200 \mathrm{mg} / \mathrm{kg}$ in mice) in endocrine therapy-resistant breast tumor models without ER mutations as compared to more recently developed SERDs administered at a BSA-calculated clinically relevant dose. Upon observing the comparable efficacy of fulvestrant above over a wide dose range administered, we sought to retrospectively relate the efficacy of fulvestrant administered at a clinically relevant dose to that observed for more recently developed oral SERDs. To validate this comparison between studies, we first compared the average fold change in tumor volume for the vehicle control groups of these studies over 4 weeks of treatment and found them to be nearly identical (Online Resource 2a). As shown in Fig. 2a, oral SERDs AZD9496, GDC0810, and bazedoxifene (BZA) inhibited the growth of TamR xenograft tumors with similar efficacy. As observed for the fulvestrant-treated TamR tumor study in Fig. 1, efficacy was not directly related to the extent of ER turnover; although all three SERDs significantly downregulated ER expression, a significant difference

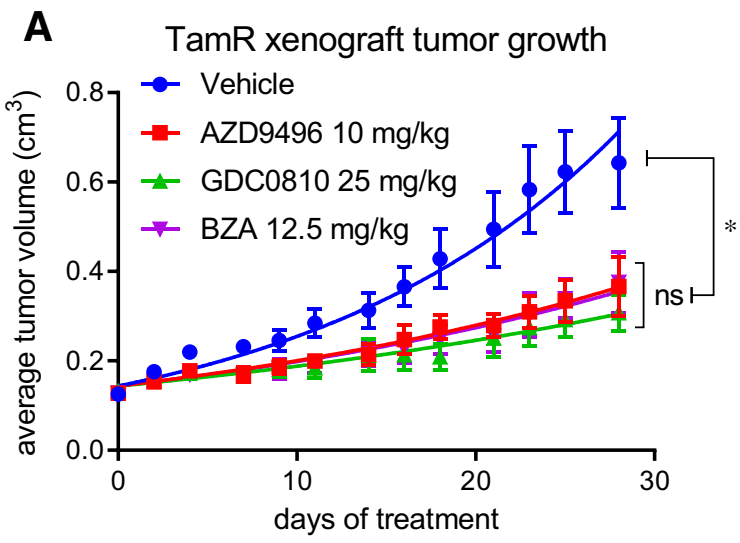

Fig. 2 Clinically relevant oral SERDs exhibit similar efficacy in tumor growth inhibition. a Tamoxifen-treated $N u: J$ mice bearing TamR xenograft tumors were randomized to treatment with vehicle (po qd), AZD9496 (10 mg/kg po qd), GDC0810 $(25 \mathrm{mg} / \mathrm{kg}$ po qd), or BZA (12.5 mg/kg po qd). Data presented indicate the average tumor volume for each group (mean \pm SEM) at each time point. *As compared to the vehicle control, significant $(p>0.05)$ inhibition of tumor growth was observed for all treatments, while no significant differences were noted between treatments (2-way ANOVA analysis could be discerned between AZD9496 and GDC0810 with respect to ER turnover (Fig. 2b). This difference was not reflected in the efficacy with which these SERDs inhibited tumor growth.

Calculation of the percent inhibition of tumor growth over time (as compared to their respective vehicle groups) for both studies included in Figs. 1 and 2 demonstrated a very similar response to the clinically relevant $(25 \mathrm{mg} / \mathrm{kg})$ dose of fulvestrant and to the oral SERDs (Table 1).

\section{Fulvestrant and oral SERDs exhibit similar efficacy in a xenograft model of resistance to estrogen deprivation}

The tamoxifen-resistant tumor model used in both of the above studies has proven predictive of clinical response of patients having endocrine therapy-resistant breast cancer to SERD administration in the clinic [18, 19]. However, the current clinical standard for first-line endocrine therapy is administration of an aromatase inhibitor (AI), enzymatic inhibitors of aromatase that block conversion of androgens to estrogens. Recent findings have shown that ESRI mutations conferring constitutive activity upon ER likely underlie resistance to AI therapy in a subset of patients, and these may impact subsequent response to SERD therapies [20-22]. However, a majority of patients lack detectable mutations in ER upon progression during AI treatments. In order to model this subset of patients, we have developed a long-term estrogen deprived (LTED) tumor model. Briefly,

B

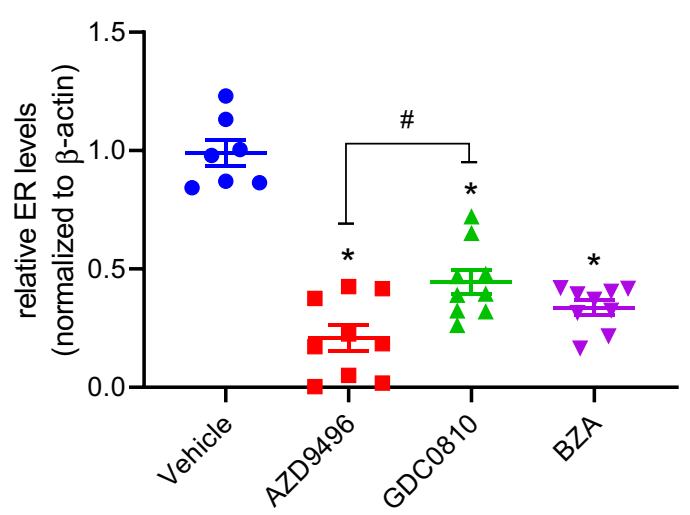

followed by Bonferroni multiple comparison test). b ER levels present in tumors harvested from mice included in a were analyzed by western blotting of tissue extracts. *A significant decrease in ER levels was observed for all SERD treatments (1-way ANOVA analysis followed by Bonferroni multiple comparison test). ${ }^{\#} p<0.05$ : Significantly less ER turnover was observed following GDC0810 treatment as compared to AZD9496. Primary western blot images are included in Suppl. Fig. 2 
Table $1 \%$ Tumor growth inhibition of TamR tumors over 4 weeks of treatment

\begin{tabular}{|c|c|c|c|c|c|c|c|}
\hline \multirow{2}{*}{$\begin{array}{l}\text { Days of } \\
\text { treatment }\end{array}$} & \multicolumn{4}{|c|}{ Fulvestrant } & \multirow[t]{2}{*}{ AZD9496 (\%) } & \multirow[t]{2}{*}{ GCD0810 (\%) } & \multirow[t]{2}{*}{ BZA $(\%)$} \\
\hline & $25(\%)$ & $50(\%)$ & $100(\%)$ & $200(\%)$ & & & \\
\hline 0 & -1 & -1 & -3 & 2 & -3 & -5 & -3 \\
\hline 2 & 25 & 24 & 23 & 28 & 13 & 11 & 11 \\
\hline 4 & 20 & 20 & 20 & 24 & 18 & 22 & 23 \\
\hline 7 & 21 & 26 & 27 & 24 & 27 & 28 & 26 \\
\hline 9 & 18 & 28 & 16 & 25 & 24 & 27 & 26 \\
\hline 11 & 24 & 31 & 32 & 39 & 30 & 35 & 33 \\
\hline 14 & 33 & 37 & 44 & 47 & 31 & 32 & 31 \\
\hline 16 & 29 & 40 & 36 & 48 & 32 & 42 & 38 \\
\hline 18 & 39 & 44 & 50 & 53 & 36 & 51 & 42 \\
\hline 21 & 44 & 51 & 46 & 61 & 43 & 49 & 48 \\
\hline 23 & 45 & 58 & 53 & 66 & 47 & 53 & 48 \\
\hline 25 & 47 & 59 & 49 & 67 & 46 & 53 & 46 \\
\hline 28 & 47 & 62 & 58 & 74 & 43 & 52 & 41 \\
\hline
\end{tabular}

estrogen treatment was withdrawn from a ovariectomized $N u: J$ mouse bearing an actively growing estrogen treated MCF7 xenograft tumor (Online Resource 3a). Following an approximate 6-months regression and stasis, the tumor regained exponential growth and became the founder tumor of an LTED xenograft tumor model that retained ER expression and can be transplanted between ovariectomized mice.

To compare the therapeutic and pharmacodynamic response of the LTED tumor model to SERD treatment, LTED tumors were established orthotopically in ovariectomized $N u: J$ mice. When tumors measured $0.1-0.15 \mathrm{~cm}^{3}$ volume, mice were randomized to 4 weeks of treatment with vehicle or clinically relevant doses of fulvestrant, AZD9496, GDC0810, BZA, or the AI letrozole. Letrozole was without effect on the growth of the LTED tumors, while all four SERDs similarly inhibited tumor growth (Fig. 3a). Comparison of the ER levels present in tumors harvested following the end of treatment demonstrated a similar extent of downregulation by all of the SERDs administered (Fig. 3b). These molecules fall largely into three chemical categories: steroidal SERDs (fulvestrant, RU58,668), acidic SERDs (GW5638 (etacstil), GDC0810, AZD9496), and basic SERDs (BZA, Rad1901 (elacestrant)). As these treatments represent different molecular subclasses of SERDs, we analyzed the effect of these regimens on uterine wet weight in the LTED tumor bearing mice following euthanasia. The rodent uterus has been used extensively to evaluate estrogenicity of compounds such as environmental estrogens and, as in this case, SERMs and SERDs. We observed no response of uterine weight to BZA or to letrozole, while a non-significant trend toward reduced uterine weight was observed for fulvestrant (Fig. 3c). Both AZD9496 and GDC0810 significantly increased uterine weight, which may suggest estrogen-like regulation of some aspects of ER activity by these compounds in this tissue.
Both of the above xenograft models originated with the exquisitely estrogen dependent MCF7 breast cancer cell line, and these models were further adapted to ER-dependent growth without estrogen treatment. Therefore, an additional breast cancer cell model was utilized to determine the broader applicability of the administration of a clinically relevant dose of fulvestrant. HCC1428 breast cancer xenograft tumors were implanted orthotopically in ovariectomized $N u: J$ mice receiving oral estradiol $(0.75 \mu \mathrm{g} / \mathrm{kg})$ treatment, a dose insufficient to support MCF7 tumor growth and intended to model those patients exhibiting incomplete estradiol suppression during AI therapy. Upon reaching $0.1-0.13 \mathrm{~cm}^{3}$ volume, mice were randomized to 4 weeks of vehicle or fulvestrant $(25 \mathrm{mg} / \mathrm{kg})$ treatment. Tumor stasis in the treated animals was observed in this xenograft model as well, showing that a clinically relevant dose of fulvestrant adequately opposed the stimulatory effects of estrogen in this model with a modest but significant downregulation of ER expression (Fig. 4).

\section{Discussion}

The initial preclinical reports of the activity of fulvestrant (ICI 182,780) described a compound with promise as a mechanistically novel approach to targeting ER activity in breast cancer, and indeed, in most preclinical models fulvestrant exhibited efficacy under conditions in which other contemporary drugs (e.g., tamoxifen, raloxifene, toremifene) were ineffective. It is still largely regarded as the only ER modulator that exhibits complete antagonist activity in vivo in all estrogen responsive tissues analyzed thus far. The initial clinical results, however, were far less promising; in the EFECT trial that enrolled patients that had already progressed during AI treatment, fulvestrant (250 mg monthly) 
Fig. 3 The clinically relevant doses of SERDs exhibited similar efficacy when compared using an estrogen deprived model of aromatase inhibitor resistance. a Ovariectomized $N u: J$ mice bearing LTED (long-term estrogen deprived) xenograft tumors were randomized to treatment with vehicle (po qd), AZD9496 (10 mg/ $\mathrm{kg}$ po qd), GDC0810 (25 mg/kg po qd), BZA (12.5 mg/kg po qd) or fulvestrant $(25 \mathrm{mg} / \mathrm{kg} \mathrm{sc} \mathrm{qw})$. Data presented indicate the average tumor volume for each group (mean \pm SEM) at each time point. *As compared to the vehicle control, significant $(p>0.05)$ inhibition of tumor growth was observed for all treatments, while no significant differences were noted between treatments (2-way ANOVA analysis followed by Bonferroni multiple comparison test). b ER levels present in tumors harvested from mice included in a were analyzed by western blotting of tissue extracts. A significant $(p<0.05)$ decrease in ER levels was observed for all SERD treatments (1-way ANOVA analysis followed by Bonferroni multiple comparison test). Primary western blot images are included in Online Resource Fig. 3b. c Weights of uteri excised after euthanasia were recorded as a measure of uterine stimulation. *A significant $(p<0.05)$ increase in uterine weight was observed for all AZD9496 and GDC0810 (1-way ANOVA analysis followed by Bonferroni multiple comparison test)

exhibited efficacy comparable to that observed for the steroidal AI anastrozole, with a $7.4 \%$ response rate and nearly identical time to progression [23]. These results largely led to general conclusion within the field that upon resistance to one endocrine therapy, breast cancer patients were unlikely to benefit from further targeting of the ER pathway, and interest in further SERD development rapidly waned.

Two key observations renewed interest in SERD development and enabled development of additional SERD compounds. First, pharmacokinetic analyses of plasma exposure at increasing doses of fulvestrant indicated that a higher dose (500 vs. $250 \mathrm{mg} / \mathrm{month}$ ), and a loading regimen in the first month of exposure $(500 \mathrm{mg}$ on d1, d14, d29) resulted in an improved response rate and increased time to progression [24-27]. Indeed, positron emission tomography/computed tomography (PET/CT) revealed that $30 \%$ of patients exhibited intratumoral [(18)F]fluoroestradiol (FES) binding during follow-up PET scans despite months of fulvestrant treatment using the originally approved $(250 \mathrm{mg} / \mathrm{month})$ treatment regimen to downregulate ER, evidence of incomplete saturation of ER binding, and insufficient fulvestrant exposure to sufficiently downregulate ER expression and/or antagonize agonist binding [28]. However, treatment-associated mutations of ER that reduce the binding affinity of fulvestrant may also contribute to low saturation of the receptor $[21,22]$. Further evaluation of this higher dose regimen in comparison to anastrozole in advanced breast cancer patients confirmed that increasing fulvestrant exposure yielded likewise increased time to progression and overall survival as compared to anastrozole $[3,29,30]$. Therefore, pharmacokinetic liabilities of fulvestrant, and not the futility of further targeting of ER, likely underlies the initially low rate and duration of response observed. Secondly, the identification of an orally bioavailable non-steroidal SERD (GW5638,

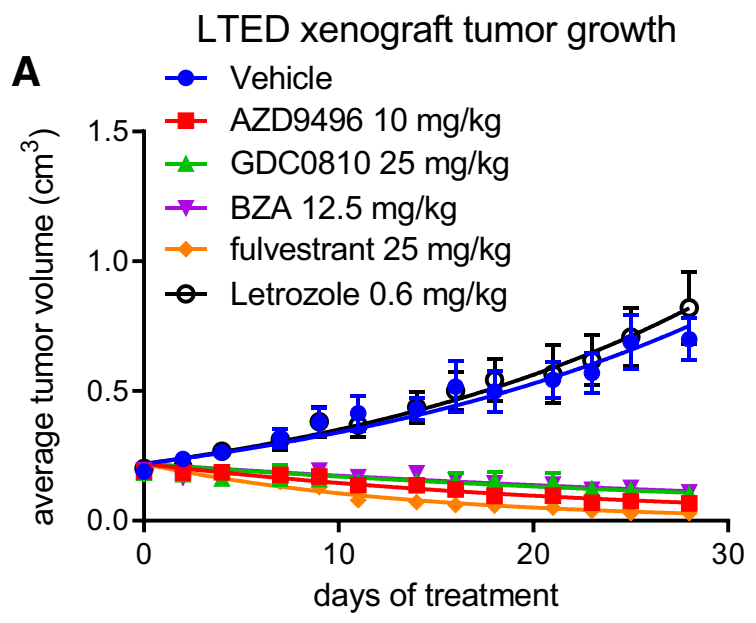

B LTED intratumoral ER expression
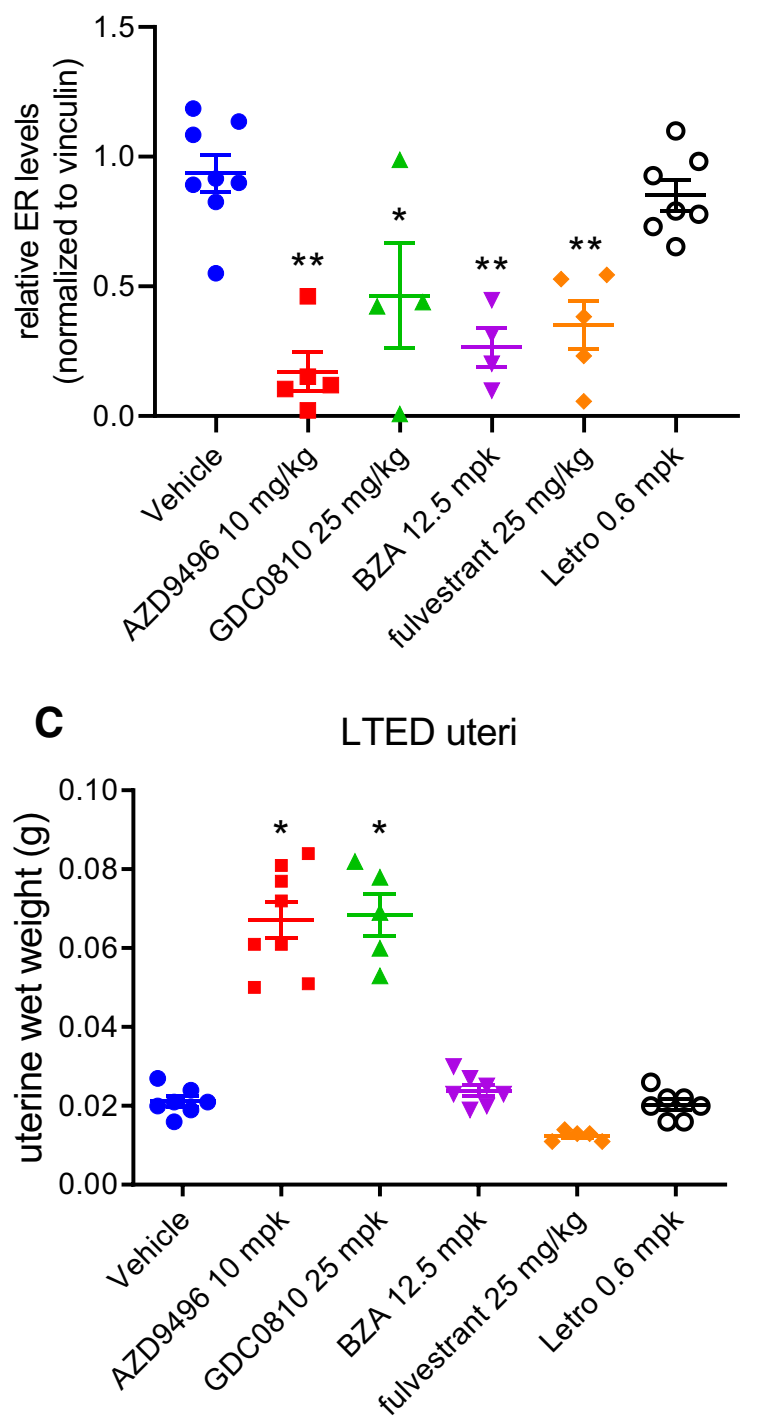


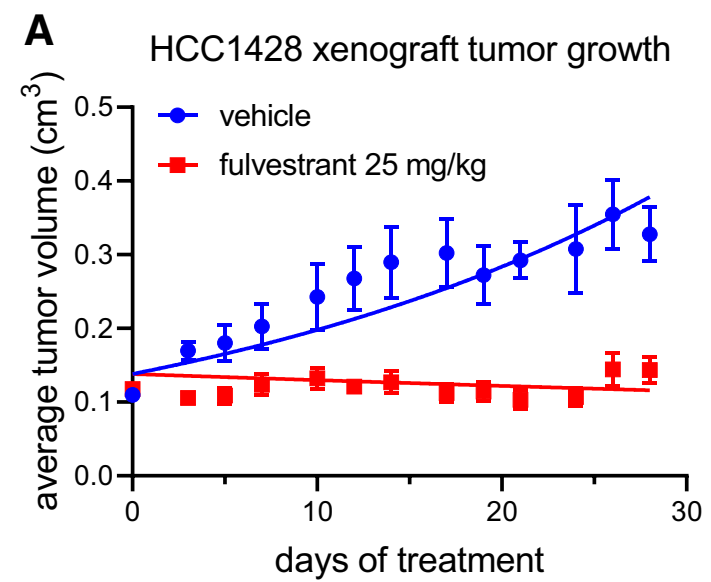

Fig. 4 A clinically relevant dose of fulvestrant inhibited estrogen dependent tumor growth. a Ovariectomized $N u: J$ mice bearing HCC1428 breast cancer xenograft tumors were randomized to treatment with vehicle or fulvestrant $(25 \mathrm{mg} / \mathrm{kg} \mathrm{sc} \mathrm{qw}) . *$ As compared to the vehicle control, significant $(p>0.05)$ inhibition of tumor growth

Etacstil) that was effective in preclinical models of endocrine therapy-resistant breast cancer and exhibited efficacy in an investigator initiated clinical trial clearly indicated that additional compounds having SERD activity could be identified and developed for clinical use [19, 31-33].

The past decade has witnessed a dramatic increase in the number of SERDs in development and entering clinical trials [34-39, 40]. Throughout their preclinical development, these compounds have been compared to fulvestrant, both in vitro and in vivo, with the goal of achieving equal or better ER downregulation and inhibition of receptor signaling in vivo as compared to fulvestrant. Comparison of the efficacy of these newly discovered compounds to a therapeutically unachievable fulvestrant exposure level may result in the selection of compounds having potential clinical liabilities at the expense of the development of other SERD compounds that might prove more tolerable. Indeed, development of several of these compounds have been discontinued following Phase I or Phase II trials for reasons relating to intolerable side effects or unexpected lack of efficacy.

In light of the difficulties experienced in advancing recently developed SERDs to the clinic, it is important to note that in at least one tumor model equivalent inhibition of tumor growth was observed for all doses of fulvestrant administered, despite the fact that post-study analysis of the tumor tissues indicated that the clinically relevant dose $(25 \mathrm{mg} / \mathrm{kg})$ did not result in significant ER downregulation. These data are in agreement with our prior in vitro findings demonstrating that the antagonist activity of fulvestrant is sufficient to block ER activity, while receptor turnover is dispensable [41]. These data raise the question whether the current path(s) of SERD development place unnecessary emphasis on potent and efficient

\section{B HCC1428 intratumoral ER expression}

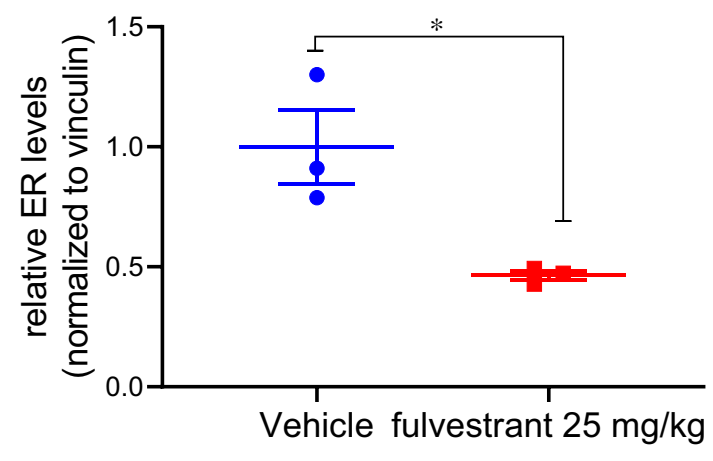

by fulvestrant was observed for multiple time points. b ER levels present in tumors harvested from mice included in a were analyzed by western blotting of tissue extracts. A significant $(p<0.05)$ decrease in ER levels was observed for fulvestrant treatment. Primary western blot images are included in Online Resource Fig. 3c

downregulation of the receptor without equal attention to the efficacy of ER inhibition independent of receptor degradation. Furthermore, a recent study has reported that the efficacy of fulvestrant and additional SERDs are mediated by their ability to slow receptor mobility as opposed to their ability to downregulate ER [42]. In essence, the imperative to develop a SERD may result in the unnecessary omission of potentially tolerable complete antagonists and/or high affinity SERMs. We believe that drug exposure and target engagement are likely to be that which has limited SERM and SERD efficacy evaluated thus far, as opposed to incomplete ER downregulation.

It is surprising that a thorough pharmacokinetic evaluation of fulvestrant in preclinical models had not been completed prior to the current study. A direct comparison of the $25 \mathrm{mg} / \mathrm{kg}$ dose predicted to be clinically relevant (based upon body surface area calculation) to that widely used in the field ( $5 \mathrm{mg} / \mathrm{mouse} ; 200 \mathrm{mg} / \mathrm{kg}$ ) indicates that the lower dose exhibits exposure comparable to that observed clinically and also efficacy in two in vivo models of endocrine therapy-resistant breast cancer. Therefore, it is anticipated that the results of this study will provide guidance for how to appropriately evaluate ER modulators and compare their efficacy to standard of care endocrine agents at exposures that are clinically relevant.

Author contributions $\mathrm{SW}, \mathrm{JB}, \mathrm{JN}$, and DM contributed to the study conception and design. Material preparation, experimental execution, and data collection were performed by SW, CC, YB, AY, KT, $\mathrm{TD}$, and KA, and data analyses were performed by SW. The first draft of the manuscript was written by SW and all authors commented on subsequent versions of the manuscript. All authors approved the final manuscript. 
Funding This study was funded in part by a sponsored research agreement with Viba Therapeutics, Inc. Supporting funding provided by the NIH (Grant Nos. R37DK048807 and CA220978), Viba Therapeutics and Potrero Hill Therapeutics.

\section{Compliance with ethical standards}

Conflict of interest Donald McDonnell received research support for this study from Viba Therapeutics and he currently serves as a consultant and as a member of their SAB. Jeremy Blitzer is a founder of Viba Therapeutics. None of the other authors have conflicts to report.

Ethical approval This article does not contain any studies with human participants performed by any of the authors. All procedures were approved by the Duke University Institutional Animal Care and Use Committee (IACUC) prior to initiating the experiment (protocol A01116-01 and A272-18-12).

Open Access This article is distributed under the terms of the Creative Commons Attribution 4.0 International License (http://creativeco mmons.org/licenses/by/4.0/), which permits unrestricted use, distribution, and reproduction in any medium, provided you give appropriate credit to the original author(s) and the source, provide a link to the Creative Commons license, and indicate if changes were made.

\section{References}

1. Burstein HJ, Lacchetti C, Anderson H, Buchholz TA, Davidson NE, Gelmon KA, Giordano SH, Hudis CA, Solky AJ, Stearns V, Winer EP, Griggs JJ (2019) Adjuvant endocrine therapy for women with hormone receptor-positive breast cancer: ASCO clinical practice guideline focused update. J Clin Oncol 37(5):423438. https://doi.org/10.1200/JCO.18.01160

2. Rugo HS, Rumble RB, Macrae E, Barton DL, Connolly HK, Dickler MN, Fallowfield L, Fowble B, Ingle JN, Jahanzeb M, Johnston SR, Korde LA, Khatcheressian JL, Mehta RS, Muss HB, Burstein HJ (2016) Endocrine therapy for hormone receptorpositive metastatic breast cancer: American Society of Clinical Oncology Guideline. J Clin Oncol 34(25):3069-3103. https://doi. org/10.1200/JCO.2016.67.1487

3. Robertson JF, Lindemann JP, Llombart-Cussac A, Rolski J, Feltl D, Dewar J, Emerson L, Dean A, Ellis MJ (2012) Fulvestrant $500 \mathrm{mg}$ versus anastrozole $1 \mathrm{mg}$ for the first-line treatment of advanced breast cancer: follow-up analysis from the randomized 'FIRST' study. Breast Cancer Res Treat 136(2):503-511. https:// doi.org/10.1007/s10549-012-2192-4

4. Perey L, Paridaens R, Hawle H, Zaman K, Nole F, Wildiers H, Fiche M, Dietrich D, Clement P, Koberle D, Goldhirsch A, Thurlimann B (2007) Clinical benefit of fulvestrant in postmenopausal women with advanced breast cancer and primary or acquired resistance to aromatase inhibitors: final results of phase II Swiss Group for Clinical Cancer Research Trial (SAKK 21/00). Ann Oncol 18:64-69

5. Ingle JN, Suman VJ, Rowland KM, Mirchandani D, Bernath AM, Camoriano JK, Fishkin PAS, Nikcevich DA, Perez EA (2006) Fulvestrant in women with advanced breast cancer after progression on prior aromatase inhibitor therapy: North Central Cancer Treatment Group Trial N0032. J Clin Oncol 24:1052-1056

6. Hu XF, Veroni M, Deluise M, Wakeling A, Sutherland R, Watts CKW, Zalcberg JR (1993) Circumvention of tamoxifen resistance by the pure antiestrogen Ici-182,780. Int J Cancer 55(5):873-876. https://doi.org/10.1002/ijc.2910550529
7. Osborne CK, Coronadoheinsohn EB, Hilsenbeck SG, Mccue BL, Wakeling AE, Mcclelland RA, Manning DL, Nicholson RI (1995) Comparison of the effects of a pure steroidal antiestrogen with those of tamoxifen in a model of human breast-cancer. J Natl Cancer Inst 87(10):746-750. https://doi.org/10.1093/jnci/87.10.746

8. Howell A, Osborne CK, Morris C, Wakeling AE (2000) ICI 182,780 (Faslodex): development of a novel, "pure" antiestrogen. Cancer 89:817-825

9. Nair AB, Jacob S (2016) A simple practice guide for dose conversion between animals and human. J Basic Clin Pharm 7(2):27-31. https://doi.org/10.4103/0976-0105.177703

10. Western blot quantitation. http://lukemiller.org/index .php/2010/11/analyzing-gels-and-western-blots-with-image-j/. Accessed 1 Sept 2019

11. Livak K, Schmittgen T (2001) Analysis of relative gene expression data using real-time quantitative PCR and the 2(DDC(T)) method. Methods 25:402-408

12. Prescribing information for faslodex. http://www.azpicentral.com/ pi.html?product=faslodex. Accessed 1 Sept 2019

13. Agrawal A, Robertson JF, Cheung KL, Gutteridge E, Ellis IO, Nicholson RI, Gee JM (2016) Biological effects of fulvestrant on estrogen receptor positive human breast cancer: short, medium and long-term effects based on sequential biopsies. Int J Cancer 138(1):146-159. https://doi.org/10.1002/ijc.29682

14. Wright TM, Wardell SE, Jasper JS, Stice JP, Safi R, Nelson ER, McDonnell DP (2014) Delineation of a FOXA1/ERalpha/AGR2 regulatory loop that is dysregulated in endocrine therapy-resistant breast cancer. Mol Cancer Res 12(12):1829-1839. https://doi. org/10.1158/1541-7786.MCR-14-0195

15. Wardell SE, Ellis MJ, Alley HM, Eisele K, VanArsdale T, Dann SG, Arndt KT, Primeau T, Griffin E, Shao J, Crowder R, Lai JP, Norris JD, McDonnell DP, Li S (2015) Efficacy of SERD/SERM hybrid-CDK4/6 inhibitor combinations in models of endocrine therapy-resistant breast cancer. Clin Cancer Res 21(22):51215130. https://doi.org/10.1158/1078-0432.CCR-15-0360

16. Joseph JD, Darimont B, Zhou W, Arrazate A, Young A, Ingalla E, Walter K, Blake RA, Nonomiya J, Guan Z, Kategaya L, Govek SP, Lai AG, Kahraman M, Brigham D, Sensintaffar J, Lu N, Shao G, Qian J, Grillot K, Moon M, Prudente R, Bischoff E, Lee KJ, Bonnefous C, Douglas KL, Julien JD, Nagasawa JY, Aparicio A, Kaufman J, Haley B, Giltnane JM, Wertz IE, Lackner MR, Nannini MA, Sampath D, Schwarz L, Manning HC, Tantawy MN, Arteaga CL, Heyman RA, Rix PJ, Friedman L, Smith ND, Metcalfe C, Hager JH (2016) The selective estrogen receptor downregulator GDC-0810 is efficacious in diverse models of ER + breast cancer. Elife. https://doi.org/10.7554/eLife.15828

17. Weir HM, Bradbury RH, Lawson M, Rabow AA, Buttar D, Callis RJ, Curwen JO, de Almeida C, Ballard P, Hulse M, Donald CS, Feron LJ, Karoutchi G, MacFaul P, Moss T, Norman RA, Pearson SE, Tonge M, Davies G, Walker GE, Wilson Z, Rowlinson R, Powell S, Sadler C, Richmond G, Ladd B, Pazolli E, Mazzola AM, D'Cruz C, De Savi C (2016) AZD9496: an oral estrogen receptor inhibitor that blocks the growth of ER-positive and ESR1-mutant breast tumors in preclinical models. Cancer Res 76(11):3307-3318. https://doi.org/10.1158/0008-5472. CAN-15-2357

18. Dardes RC, O'Regan RM, Gajdos C, Robinson SP, Bentrem D, De Los Reyes A, Jordan VC (2002) Effects of a new clinically relevant antiestrogen (GW5638) related to tamoxifen on breast and endometrial cancer growth in vivo. Clin Cancer Res $8(6): 1995-2001$

19. Connor CE, Norris JD, Broadwater G, Willson TM, Gottardis MM, Dewhirst MW, McDonnell DP (2001) Circumventing tamoxifen resistance in breast cancers using antiestrogens that induce unique conformational changes in the estrogen receptor. Cancer Res 61(7):2917-2922 
20. Fanning SW, Mayne CG, Dharmarajan V, Carlson KE, Martin TA, Novick SJ, Toy W, Green B, Panchamukhi S, Katzenellenbogen BS, Tajkhorshid E, Griffin PR, Shen Y, Chandarlapaty S, Katzenellenbogen JA, Greene GL (2016) Estrogen receptor alpha somatic mutations Y537S and D538G confer breast cancer endocrine resistance by stabilizing the activating function-2 binding conformation. Elife. https://doi.org/10.7554/eLife.12792

21. Toy W, Shen Y, Won H, Green B, Sakr RA, Will M, Li Z, Gala K, Fanning S, King TA, Hudis C, Chen D, Taran T, Hortobagyi G, Greene G, Berger M, Baselga J, Chandarlapaty S (2013) ESR1 ligand-binding domain mutations in hormone-resistant breast cancer. Nat Genet 45(12):1439-1445. https://doi.org/10.1038/ ng. 2822

22. Robinson DR, Wu YM, Vats P, Su F, Lonigro RJ, Cao X, KalyanaSundaram S, Wang R, Ning Y, Hodges L, Gursky A, Siddiqui J, Tomlins SA, Roychowdhury S, Pienta KJ, Kim SY, Roberts JS, Rae JM, Van Poznak CH, Hayes DF, Chugh R, Kunju LP, Talpaz M, Schott AF, Chinnaiyan AM (2013) Activating ESR1 mutations in hormone-resistant metastatic breast cancer. Nat Genet 45(12):1446-1451. https://doi.org/10.1038/ng.2823

23. Chia S, Gradishar W, Mauriac L, Bines J, Amant F, Federico M, Fein L, Romieu G, Buzdar A, Robertson J, Brufsky A, Possinger K, Rennie P, Sapunar F, Lowe E, Piccart M (2008) Double-blind, randomized placebo controlled trial of Fulvestrant compared with exemestane after prior nonsteroidal aromatase inhibitor therapy in postmenopausal women with hormone receptor-positive, advanced breast cancer: results from EFECT. J Clin Oncol 26(10):1664-1670

24. Robertson JFR (2007) Fulvestrant (Faslodex)-how to make a good drug better. Oncologist 12:774-784

25. Di Leo A, Jerusalem G, Petruzelka L, Torres R, Bondarenko IN, Khasanov R, Verhoeven D, Pedrini JL, Smirnova I, Lichinitser MR, Pendergrass K, Garnett S, Lindemann JP, Sapunar F, Martin M (2010) Results of the CONFIRM phase III trial comparing fulvestrant $250 \mathrm{mg}$ with fulvestrant $500 \mathrm{mg}$ in postmenopausal women with estrogen receptor-positive advanced breast cancer. J Clin Oncol 28(30):4594-4600. https://doi.org/10.1200/ JCO.2010.28.8415

26. Di Leo A, Jerusalem G, Petruzelka L, Torres R, Bondarenko IN, Khasanov R, Verhoeven D, Pedrini JL, Smirnova I, Lichinitser MR, Pendergrass K, Malorni L, Garnett S, Rukazenkov Y, Martin M (2014) Final overall survival: fulvestrant $500 \mathrm{mg}$ vs $250 \mathrm{mg}$ in the randomized CONFIRM trial. J Natl Cancer Inst 106(1):djt337. https://doi.org/10.1093/jnci/djt337

27. Leo AD, Jerusalem G, Petruzelka L, Torres R, Bondarenko I, Khasanov R, Verhoeven D, Pedrini J, Lichinitser M, Pendergrass K, Garnett S, Lindermann J, Sapunar F, Martin M (2009) CONFIRM: a Phase III, randomized, parallel-group trial comparing fulvestrant $250 \mathrm{mg}$ vs fulvestrant $500 \mathrm{mg}$ in postmenopausal women with estrogen receptor-positive advanced breast cancer. Cancer Res 69(24 Suppl):25

28. van Kruchten M, de Vries EG, Glaudemans AW, van Lanschot MC, van Faassen M, Kema IP, Brown M, Schroder CP, de Vries EF, Hospers GA (2015) Measuring residual estrogen receptor availability during fulvestrant therapy in patients with metastatic breast cancer. Cancer Discov 5(1):72-81. https://doi. org/10.1158/2159-8290.CD-14-0697

29. Robertson JF, Llombart-Cussac A, Rolski J, Feltl D, Dewar J, Macpherson E, Lindemann J, Ellis MJ (2009) Activity of fulvestrant $500 \mathrm{mg}$ versus anastrozole $1 \mathrm{mg}$ as first-line treatment for advanced breast cancer: results from the FIRST study. J Clin Oncol 27(27):4530-4535

30. Ellis MJ, Llombart-Cussac A, Feltl D, Dewar JA, Jasiowka M, Hewson N, Rukazenkov Y, Robertson JF (2015) Fulvestrant $500 \mathrm{mg}$ versus anastrozole $1 \mathrm{mg}$ for the first-line treatment of advanced breast cancer: overall survival analysis from the phase
II FIRST study. J Clin Oncol 33(32):3781-3787. https://doi. org/10.1200/JCO.2015.61.5831

31. Wijayaratne A, McDonnell D (2001) The human estrogen receptor-a is a ubiquitinated protein whose stability is affected differentially by agonists, antagonists, and selective estrogen receptor modulators. J Biol Chem 276(38):35684-35692

32. Wijayaratne A, Nagel S, Paige L, Christensen D, Norris J, Fowlkes D, McDonnell D (1999) Comparative analysis of mechanistic difference among antiestrogens. Endocrinology 140(12):5828-5840

33. Willson TM, Norris JD, Wagner BL, Asplin I, Baer P, Brown HR, Jones SA, Henke B, Sauls H, Wolfe S, Morris DC, McDonnell DP (1997) Dissection of the molecular mechanism of action of GW5638, a novel estrogen receptor ligand, provides insights into the role of ER in bone. Endocrinology 138:3901-3911

34. Burks HE, Abrams T, Kirby CA, Baird J, Fekete A, Hamann LG, Kim S, Lombardo F, Loo A, Lubicka D, Macchi K, McDonnell DP, Mishina Y, Norris JD, Nunez J, Saran C, Sun Y, Thomsen NM, Wang C, Wang J, Peukert S (2017) Discovery of an acrylic acid based tetrahydroisoquinoline as an orally bioavailable selective estrogen receptor degrader for ERalpha + breast cancer. J Med Chem 60(7):2790-2818. https://doi.org/10.1021/acs.jmedc hem.6b01468

35. Nagasawa J, Govek S, Kahraman M, Lai A, Bonnefous C, Douglas K, Sensintaffar J, Lu N, Lee K, Aparicio A, Kaufman J, Qian J, Shao G, Prudente R, Joseph JD, Darimont B, Brigham D, Maheu K, Heyman R, Rix PJ, Hager JH, Smith ND (2018) Identification of an orally bioavailable chromene-based selective estrogen receptor degrader (SERD) that demonstrates robust activity in a model of tamoxifen-resistant breast cancer. J Med Chem 61(17):79177928. https://doi.org/10.1021/acs.jmedchem.8b00921

36. Nardone A, Weir H, Delpuech O, Brown H, De Angelis C, Cataldo ML, Fu X, Shea MJ, Mitchell T, Veeraraghavan J, Nagi C, Pilling M, Rimawi MF, Trivedi M, Hilsenbeck SG, Chamness GC, Jeselsohn R, Osborne CK, Schiff R (2019) The oral selective oestrogen receptor degrader (SERD) AZD9496 is comparable to fulvestrant in antagonising ER and circumventing endocrine resistance. Br J Cancer 120(3):331-339. https://doi.org/10.1038/ s41416-018-0354-9

37. Tria GS, Abrams T, Baird J, Burks HE, Firestone B, Gaither LA, Hamann LG, He G, Kirby CA, Kim S, Lombardo F, Macchi KJ, McDonnell DP, Mishina Y, Norris JD, Nunez J, Springer C, Sun Y, Thomsen NM, Wang C, Wang J, Yu B, Tiong-Yip CL, Peukert S (2018) Discovery of LSZ102, a potent, orally bioavailable selective estrogen receptor degrader (SERD) for the treatment of estrogen receptor positive breast cancer. J Med Chem 61(7):28372864. https://doi.org/10.1021/acs.jmedchem.7b01682

38. Hattersley G, David F, Harris A, Clarkin M, Banks K, Williams G, Glaudemans A, Doorduin J, Koole M, de Vries E, Lyttle R (2014) RAD1901, a novel tissue-selective estrogen receptor degrader (SERD) demonstrates estrogen receptor engagement in a phase 1 clinical study. Paper presented at the San Antonio Breast Cancer Meeting, San Antonio, Texas, United States of America, December 9-13, 2014

39. Lai A, Kahraman M, Govek S, Nagasawa J, Bonnefous C, Julien J, Douglas K, Sensintaffar J, Lu N, Lee KJ, Aparicio A, Kaufman J, Qian J, Shao G, Prudente R, Moon MJ, Joseph JD, Darimont B, Brigham D, Grillot K, Heyman R, Rix PJ, Hager JH, Smith ND (2015) Identification of GDC-0810 (ARN-810), an orally bioavailable selective estrogen receptor degrader (SERD) that demonstrates robust activity in tamoxifen-resistant breast cancer xenografts. J Med Chem 58(12):4888-4904. https://doi.org/10.1021/ acs.jmedchem.5b00054

40. Kahraman M, Govek SP, Nagasawa JY, Lai A, Bonnefous C, Douglas K, Sensintaffar J, Liu N, Lee K, Aparicio A, Kaufman J, Qian J, Shao G, Prudente R, Joseph JD, Darimont B, Brigham D, Heyman R, Rix PJ, Hager JH, Smith ND (2019) Maximizing 
ER-alpha degradation maximizes activity in a tamoxifen-resistant breast cancer model: identification of GDC-0927. ACS Med Chem Lett 10(1):50-55. https://doi.org/10.1021/acsmedchem lett.8b00414

41. Wardell SE, Marks JR, McDonnell DP (2011) The turnover of estrogen receptor alpha by the selective estrogen receptor degrader (SERD) fulvestrant is a saturable process that is not required for antagonist efficacy. Biochem Pharmacol 82(2):122-130. https:// doi.org/10.1016/j.bcp.2011.03.031

42. Guan J, Zhou W, Hafner M, Blake RA, Chalouni C, Chen IP, De Bruyn T, Giltnane JM, Hartman SJ, Heidersbach A, Houtman R, Ingalla E, Kategaya L, Kleinheinz T, Li J, Martin SE, Modrusan
Z, Nannini M, Oeh J, Ubhayakar S, Wang X, Wertz IE, Young A, Yu M, Sampath D, Hager JH, Friedman LS, Daemen A, Metcalfe C (2019) therapeutic ligands antagonize estrogen receptor function by impairing its mobility. Cell 178(4):949-963. https://doi. org/10.1016/j.cell.2019.06.026

Publisher's Note Springer Nature remains neutral with regard to jurisdictional claims in published maps and institutional affiliations. 